\title{
Interpelações à Igreja
}

\section{A GRAÇA DE DEUS E A REFORMA NA IGREJA}

THE GRACE OF GOD AND THE REFORM IN THE CHURCH

\author{
José Neivaldo de Souza*
}

\section{RESUMO}

O presente estudo tem por objetivo abordar o problema da graça de Deus e a Reforma na Igreja. Quer entender, à luz da epístola de Paulo aos Efésios (2,8-10), o que é a graça divina e qual sua importância na teologia cristã. Ainda, nessa direção, compreender o contexto sociopolítico-religioso que fez o apóstolo escrever àquela comunidade e como, tendo como princípio a graça cristã, pôde trazer renovação àquela comunidade.

Palavras-chave: Graça. Éfeso. Jesus. Igreja. Salvação.

\section{ABSTRACT}

This study aims to address the problem of God's grace and the Reformation in the Church. Want to understand in light of Paul's epistle to the Ephesians (2.8-10), which divine grace and what is its importance in Christian theology. Still, in this direction, understand the social, political and religious context that made the apostle write to that community and how, with the principle of Christian grace, could bring renewal to that community.

Keywords: Grace. Ephesus. Jesus. Church. Salvation.

* Doutor em Teologia e mestre em Psicologia Clínica e Filosofia. Professor da Faculdade Teológica Batista do Paraná (FTBP) e Faculdade Evangélica do Paraná (FEPAR). Membro da Sociedade de Teologia e Ciências da Religião. E-mail: <Neivaldo.js@gmail.com>.

\begin{tabular}{|l|l|l|l|l|l|}
\hline Teocomunicação & Porto Alegre & v. 45 & n. 1 & p. 59-71 & jan.-abr. 2015 \\
\hline
\end{tabular}




\section{Introdução}

O presente artigo visa apresentar uma reflexão sobre a Igreja e a graça de Deus à luz da epístola de Paulo aos Efésios (2,8-10). Graça, entre outros significados, é um conceito bíblico e aponta para a ação gratuita de Deus. Ela é dom incondicional e independe dos méritos pessoais. A fé é necessária à graça? Do ponto de vista teológico, somente Deus é necessário, porém, a fé é um meio essencial, por onde circula toda interpretação, clareza e comunicação do mistério trinitário.

Sem os óculos da fé, a graça é ignorada e conceitos como Deus, Jesus e Igreja não passam de pura ideologia para fortalecer o status quo vigente de uma determinada cultura ou sociedade. Pela fé, tais conceitos se enchem de sentido e sua verdade transcende o mundo presente, apontando para outro Reino, onde perdão, fraternidade e cuidado não se reduzem a práticas da lei, mas se projetam como uma relação de amor (Mc 12,33; 1Jo 4,20).

Não basta viver, é preciso "com-viver". A graça exige alteridade. $\mathrm{O}$ ofensor dirige-se ao ofendido e, num ato de liberdade e humildade, pede perdão. Da mesma forma, o ofendido, ao liberar perdão, atualiza a ação gratuita de Deus, cuidando para que ninguém se perca ( $J r$ 23,4; $J o 6,37)$. A fé é certeza de que a graça de Deus se faz presente na medida em que o cuidar de si se redunda em cuidar do outro e da criação.

Graça e fé se encarnam, de forma absoluta, numa pessoa: Jesus Cristo. No Filho, a salvação não é uma mercadoria a ser negociada e nem vem dos méritos do conhecimento, mas fruto do amor incondicional do Pai. Paulo observa que, em Cristo, "pela graça" e "mediante a fé", se cumpre o dom de Deus: a salvação da humanidade $(E f 2,8)$.

John Stott, ${ }^{1}$ sob a teologia paulina, observa que, antes de Jesus, o mundo era interpretado sob a ótica da lei, da ira e do poder, como bem diz o Salmo: "Quarenta anos esta geração me desgostou, e eu disse: Sempre os corações errantes, que não conhecem meus caminhos... Então eu jurei na minha ira: jamais entrarão no meu repouso" (Sl 95,10-11). Sob a ética do amor e da humildade, os primeiros cristãos enxergam em Cristo a "Verdade" sobre a relação amorosa entre Deus e a humanidade. A partir dele, surge uma nova hermenêutica, pois Deus "recapitula" nele todas as coisas $(E f 1,10)$. Pela graça encarnada, Deus perdoa a humanidade e a coloca numa posição de honra.

STOTT, John R. W. - A Bíblia fala hoje. A Mensagem de Efésios, 1987. 
O objetivo desta reflexão é pensar três questões, diversas, porém tão íntimas: a graça, a fé e a reforma da Igreja. A hipótese a ser levantada, ao longo deste raciocínio, é simples: em primeiro lugar, questionar a posição segundo a qual a salvação chega à Igreja por méritos pessoais; em segundo, a fé é um processo através do qual a salvação, por pura graça, se manifesta e, em terceiro, a salvação é iniciativa gratuita de Deus e o trabalho da Igreja é ser sinal dessa realidade na terra.

À luz da Epístola aos Efésios, especificamente 2,8-10, o texto pretende trazer luzes que iluminem tais questões e busquem saídas práticas para uma Igreja constantemente em reforma.

\section{Fora da Graça não há Salvação}

É importante ressaltar o contexto sócio-político-religioso sob o qual o autor expressa seu anúncio. A cidade de Éfeso, apesar de colônia romana, era próspera e bem edificada, devido a sua localização. A quatro quilômetros do mar Egeu, não só preservava vários canais de saída para o mar, facilitando o acesso ao porto marítimo, mas também conservava rotas por onde circulavam as caravanas em direção ao oriente. Devido ao controle romano, suas estradas eram bem construídas e conservadas; possuía, se não o maior, um dos maiores aquedutos da região, em homenagem ao Imperador Augusto. Um monumento de dois andares, todo revestido em mármore. Segundo Crossan e Reed (2007, p. 227), "o projeto patrocinado pelo expatriado romano C. Sextilius Pollio, pela esposa e pelo filho, foi edificado em honra de Augusto para suprir os inúmeros balneários da cidade".

A boa relação entre o governo de Éfeso e o imperador romano se estendia em todas as áreas da cultura, principalmente nos cultos religiosos e na colocação de oficiais para os rituais divinos. Os sacerdotes eram indicados segundo sua influência política, e seu ofício reduzia-se em oferecer sacrifícios e em manter a paz entre Roma e os deuses.

Crossan e Reed (2007, p. 231) descrevem o controle do Estado sobre a religiosidade. Observam que era interesse de Roma incluir em seu Panteão outras divindades estrangeiras, por isso não foi difícil incentivar o culto à Diana, deusa dos efésios. Nessa relação amigável entre a divina deusa e o divino imperador que, por algum tempo, foi o salvador dos povos colonizados, se estabeleceu a Pax romana e o controle sobre a fé religiosa. O "divino" Augusto era aclamado como "Senhor" e louvado pela classe dos senadores e governadores das colônias romanas. 
Em Éfeso, sob a custódia romana, se destacava o templo de Artêmis, deusa conhecida como "Diana dos Efésios". ${ }^{2}$ A vida cotidiana dos cidadãos era influenciada pela adoração a essa divindade, retratada em uma grande imagem, no interior do templo. A indústria, o comércio e até o lazer das pessoas eram grandemente influenciados por essa crença, porém quem ousasse se desviar do controle senatorial era reprimido, politicamente e religiosamente. Estado e religião, duas realidades que se confluíam ao único poder: Roma.

O imperador Augusto, por um lado, havia desintegrado o controle imperial e apaziguado a população arrasada pelas guerras civis romanas, mas, por outro lado, era conivente com o uso da força e da violência, quando dizia respeito ao controle social: a sexualidade era controlada através do patriarcalismo e as nações, pelo imperialismo.

As práticas religiosas inadequadas, aos olhos de Roma, eram violentamente reprimidas e a estratégia romana de dividir para imperar se fazia presente na fé: a divisão começava desde a família, onde mulheres, submissas e controladas pelos maridos, deviam se sujeitar a uma organização sociopatriarcal-imperial. O "evangelho" do Império, nada teológico, porém carregado de uma ideologia senhorial esparramada ao longo do mediterrâneo, nada mais era senão a imposição de um poder ligado às riquezas deste mundo, por isso evangelho das trevas e da morte.

Hoje restam apenas ruínas daquela que chegou a ser uma grande metrópole, capital da província. As ruínas demonstram sua riqueza: a via Acadiana, quinhentos metros de extensão, toda pavimentada de mármore; um teatro romano para 25 mil lugares; um estádio para jogos; um templo dedicado a Ártemis etc. Ao ler a carta de Paulo, o leitor se confrontará com esta realidade e entenderá a proposta do apóstolo. Diante do poder imperial cujo domínio aponta para a cegueira e manipulação das pessoas, a "Boa Nova" de Jesus Cristo é anunciada como caminho sobre o qual a Graça de Deus liberta e conduz à salvação.

\section{Jesus Cristo e a Encarnação da Graça}

Éfeso se tornou também uma cidade estratégica para o trabalho missionário de Paulo na Ásia. É em confronto com este sistema que ele vai apresentar seu evangelho e nele revelar o verdadeiro Senhor

${ }_{2}$ Cf. Bíblia de Estudos - Palavras-chave: Hebraico e Grego. 2. ed. rev. e cor., 2011, p. 1233. 
e Salvador, filho de Deus. Sua proposta é teológico-cristológica e desmantela uma ideologia cujo intento é manter uma estrutura social de classes construída sobre a idolatria do poder. Qual é a alternativa para este mundo? A passagem de $E f 2,1-10$, para muitos estudiosos, é a colocação mais objetiva de Paulo e aparece em quase todas as cartas. A mensagem é clara: a salvação vem pela graça, através da fé, não pelas boas obras. A fé deve ser dirigida a Deus e não às ações humanas.

O problema da graça está presente na Sagrada Escritura desde o Primeiro Testamento, cujo contexto denota uma cultura mais antiga e bem diferente daquela vivida nos primeiros séculos da Igreja cristã. Nas Cartas Paulinas, ela tem um enfoque puramente cristológico, como expressa a epístola aos Efésios. Para o autor desta carta, ${ }^{3}$ a compreensão da graça de Deus só é possível pela fé em Jesus Cristo.

A partir de Efésios 2,8-10, pode-se entender a graça como mensagem central. Assim escreve ele:

8. Pela graça fostes salvos, por meio da fé, e isso não vem de vós, é dom de Deus.

9. Não vem das obras, para que ninguém se encha de orgulho.

10. Pois somos criaturas dele, criados em Cristo Jesus para as boas obras que Deus já antes tinha preparado para que nelas

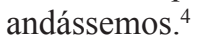

Num contexto literário mais próximo (Ef 2,1-10), o autor trata primeiramente do estado espiritual da comunidade à qual ele se dirige (v. 1-3), descrevendo a situação de morte daqueles que vivem fora da graça: são filhos da ira de Deus e vivem sob o domínio das trevas; em seguida, o autor chama atenção para a obra realizada e operada por Deus, no interior da comunidade (v. 4-7); por último, destaca o propósito desta missão: a salvação vem pela graça, é fruto da benevolência divina que, em Jesus se manifestou (v. 8-10).

Analisando algumas traduções, percebe-se que não há diferenças, no que se refere ao começo do versículo 8. A Bíblia Almeida Corrigida e Fiel usa as palavras: "Pela graça sois salvos"; a NVI (Nova Versão Internacional) traduz: "Pois vocês são salvos pela graça" e a Bíblia de Jerusalém: "Pela graça fostes salvos". As três versões não se diferem

\footnotetext{
3 O Corpus paulinum é composto de quatorze epístolas das quais 2 Tessalonicenses, Colossenses, Efésios, 1 e 2 Timóteo e Tito. A carta aos Efésios é considerada deuteropaulina, por ser "supostamente" escrita pelo apóstolo.

4 Cf. Tradução Bíblia de Jerusalém. São Paulo: Paulinas, 1973.
} 
quanto ao conteúdo do The Greek New Testament que, traduzido literalmente, diz: "Pela pois graça sois salvos".

No versículo 9, as três versões são também semelhantes e, no versículo 10, a Bíblia Almeida Corrigida e Fiel começa da seguinte forma: "Porque somos feitura sua, criados em Cristo Jesus para as boas obras...", enquanto que a Nova Versão Internacional diz: "Porque somos criação de Deus, realizada em Cristo Jesus, para fazermos boas obras..."; e a Bíblia de Jerusalém traduz: "Pois somos criaturas dele, criados em Cristo Jesus para boas obras...”. Este versículo apresenta, nas três versões, dois termos diferentes, porém com o mesmo sentido: "feitura sua" (Bíblia Almeida Corrigida); na NVI aparece: "criação de Deus"; e na Bíblia de Jerusalém: "criaturas dele".

Feitura, criação e criaturas. Traduções diversas para designar a maneira como algo foi feito. É a obra, o trabalho, enfim, a produção. Apesar de grafias diferentes, o sentido não muda: o ser criado é tirado do nada por seu Criador e isso é obra da graça. A ideia de criação aparece mais claramente nesta carta e a ela, a Igreja, enquanto "corpo de Cristo", tem que se encaixar. Sobre isso escreve Harrington (1974, p. 551):

Além dos cristãos que são o 'Corpo' propriamente dito, a igreja abarca, de algum modo, todas as forças da nova criação que é cumulada pelo poder do Senhor ressuscitado. Porquanto o Cristo ressuscitado é a célula inicial do novo mundo; nele Deus recriou a humanidade $(E f 4,24)$ e 'uniu' o universo $(E f 1,10)$. Contém, assim, em si mesmo, toda a plenitude de Deus e do novo cosmos (cf. $\mathrm{Cl} 2,9$ ); e os que se unem a Cristo são, por este fato, imersos na sua plenitude $(E f 3,19 ; 4,13$; cf. $C l$ 2,10). A amplitude cósmica da concepção de Colossenses é, efetivamente, mantida em Efésios, mas sempre em relação ao conceito de igreja.

A carta aos Efésios expressa o pensamento e a ação de um autor. Ela não foi questionada, quanto à sua autoria, até o século XIX, quando a teologia liberal se dobra sobre o contexto sociopolítico-literário da época.

Paulo traz aos efésios uma explicação sobre algo incompreensível a eles. Provavelmente surgiram questionamentos acerca da salvação. Há nesta frase um dativo de causa: "pela" graça ou "por causa" da graça. Ela é a base, o alicerce da salvação humana e sua compreensão se dá pela 
fé. Esta não é uma ação puramente humana, é graça de Deus, através da qual se pode acessar o mistério da salvação.

A graça de Deus é o conteúdo da salvação e a fé é a forma pela qual a humanidade recebe esta mensagem; se a primeira é fundamento da obra salvífica, a segunda é a resposta pronta e pessoal à gratuidade divina. Paulo deixa a entender que, apesar da fé, a graça ou o poder que leva à salvação não vêm do ser humano: "e isso não vem de vós". Não há mérito pessoal em adquirir a salvação. Em outras palavras, a economia da salvação independe do investimento da fé, porém, por meio desta, a salvação se torna mais crível.

Pelo que indica o contexto, pode-se saber o quanto Paulo revolucionou aquela sociedade. Não foram poucas as pessoas que, ao abandonar o seu passado de misticismo, se converteram ao evangelho pregado pelo cidadão de Tarso. Provavelmente essas pessoas, ao mudarem os seus rumos, provocaram uma mudança nos hábitos e costumes daquela gente. Por exemplo: os ourives e negociantes de imagens ganhavam a vida comercializando artigos religiosos em favor do culto de Ártemis. Eles não se alegraram e, por isso, insuflaram no povo uma revolta, de tal forma que Paulo, meio que às pressas, teve que deixar Éfeso. Nos Atos dos Apóstolos (At 19, 23-40), Lucas narra este episódio observando que o ourives Demétrio reuniu todos que trabalhavam na fabricação de artigos religiosos e convocou-os a uma assembleia a fim de insuflar na multidão uma revolta contra Paulo e seus companheiros. Assim diz o texto (At 19, 25-27):

Amigos, sabeis que é deste ganho que provém o nosso bem-estar. Entretanto, vedes e ouvis que não somente em Éfeso, mas em quase toda a Ásia, este Paulo tem desencaminhado, com suas persuasões, uma multidão considerável: pois diz que não são deuses os que são feitos por mãos humanas. Isto não só traz o perigo de a nossa profissão cair em descrédito, mas também o próprio templo da grande deusa Ártemis perderá todo o seu prestígio, sendo logo despojada de sua majestade aquela que toda a Ásia e o mundo veneram.

Cheios de ira, as pessoas que se encontravam ali foram para o teatro exigir o julgamento de Paulo e seus amigos (At 19, 28-34). O motim só não continuou devido a um escrivão (At 19, 35-40) que se colocou diante do público. Apaziguando a situação, observou que não 
havia nos apóstolos intenção de sacrilégio ou blasfêmia contra a deusa de Éfeso.

A pregação de Paulo atrapalhou não só vida comercial daquela cidade, como também provocou uma transformação naquilo que lhe era essencial: a fé. Essa postura exigiria algumas mudanças éticas: teriam que abandonar a idolatria e aderir a uma pessoa: Jesus Cristo; teriam que reelaborar o conceito de salvação que, até então, era ligado ao poder político e ao esforço de cada um no agrado à Diana; teriam que se comprometer a transformar certos rituais de influência ocultista em celebração monoteísta, cujo centro está numa confissão: "Jesus Cristo é o Senhor".

Crossan e Reed (2007, p. 248) observam que ao evangelho da escravidão Paulo propõe o evangelho da liberdade onde se estabelece uma nova criação. Esta novidade é apresentada em três resumo-clímax: 1. A humanidade é chamada à liberdade através do evangelho da glória de Deus: Jesus Cristo; 2. Por esta liberdade a criação, como filhos de Deus, goza da glória divina; 3. A nova criação é encarnação da "boa nova" global de Deus através de Cristo Jesus. Este novo evangelho contraria o "evangelho" de Augusto e sua ideologia idolatrada na imagem de Ártemis. Na idolatria e sem liberdade as pessoas dependem dos favores ilusórios dos deuses. Paulo, à luz das Antigas Escrituras, entendia que a humanidade está "morta" por conta do pecado de Adão e somente Deus pode salvá-la de tal situação. Segundo ele, por misericórdia, Deus mandou o seu Filho para que o mundo aprendesse a ser luz e amasse uns aos outros. Por meio de Cristo, Deus demonstra sua graça e isso não é pelos méritos humanos, mas por puro amor. Acerca disso, escrevem Radmacher; Allen; House (2010, p. 505):

Dom de Deus. Não há nada que possamos fazer para obter a nossa salvação. Alguns sugerem que o dom de Deus modifica a palavra fé neste versículo. Portanto, Paulo estava dizendo que nem nossa fé em Deus (que permite que tomemos posse da salvação) provém de nós mesmos. Ela também é um dom, por isso ninguém pode orgulhar-se de sua condição de membro do Corpo de Cristo. Recebemos tudo de nosso Pai misericordioso e bondoso.

Se não há nada a fazer, por parte do ser humano, em favor de sua salvação, uma coisa é possível aceitar: a salvação vem da pura graça divina e ela só pode ser entendida no corpo de Cristo. Na carta aos 
Efésios, percebe-se claramente o quanto a graça de Deus é atuante. O autor lembra o passado da comunidade ressaltando sua distância em relação a Cristo, portanto, à graça. Ao apresentar Jesus, observa que, agora, enquanto corpo de Cristo, a Igreja, fundada sob seus apóstolos, torna-se não só o alvo da graça divina, mas a principal e responsável por sua difusão.

\section{Pela Graça a Igreja se Reforma}

O conteúdo da carta aos efésios projeta, como num espelho, a ideia que toda Bíblia tem sobre a graça divina. Paulo destina a esta igreja, como se referisse à humanidade, uma mensagem nova: A verdade sobre a graça deve ser interpretada segundo a necessidade de viver como Jesus viveu. Ele é o modelo e Nele a graça continua atuante, e a Igreja, que se estende sobre toda terra, como corpo universal de Cristo, é responsável por anunciar e viver esta novidade.

O termo grego "Ekklesia", utilizado por Paulo, na carta aos efésios, tem conotação diferente das outras cartas. Ele tem sentido universal e não local, trata do Corpo de Cristo, fundamentado nos apóstolos e profetas (2.20). A fé da Igreja só é essencial se esta tem a consciência de sua "mediação", isto é, de que a justificação não vem de si mesma, mas de Deus, como escreve Souza (2010, p. 17): "Martinho Lutero reformulou o conceito de fé, à luz da teologia paulina, observando que, através dela, Deus justifica o ser humano: "o justo viverá pela fé"."

A Igreja não só deve cultivar a fé, que é dom da graça, mas vivê-la intensamente na expectativa da salvação; não pode se orgulhar e tampouco se colocar como detentora da graça, mas pode, na presença do Espírito Santo, colocar-se como serva, lembrando-se não só de sua condição pecaminosa, mas do chamado à salvação por Cristo Jesus. Chamada a agir, graciosamente, implantando o Reino de Deus no coração humano, à imagem de Cristo, ela busca a ovelha desviada e acolhe com humildade aquele que se arrepende. Em outras palavras, a Igreja é responsável por se opor ao reino da "desgraça", sendo o lugar terapêutico cujos remédios são expressão da graça, como bem observa Yancey: "É a única força do universo suficientemente poderosa para quebrar as cadeias que escravizam gerações. Apenas a graça derrete a não graça".

Paulo, ao escrever aos efésios, quer ressaltar o papel da Igreja enquanto corpo de Cristo. Ela é, assim como o próprio Jesus, o lugar 
por onde a graça passeia; o lugar por excelência do "evangelho da graça de Deus". O apóstolo exortou à comunidade, naquele tempo, e hoje, ao reler esta carta, as igrejas interpretam-na a fim de compreender, de fato, como viver esta graça segundo a vontade de Deus, em Cristo Jesus.

Yancey, ao perguntar se a graça de Deus é transmitida corretamente, lembra S. Brown que faz uma analogia interessante com o atendimento veterinário. Segundo ele, basta observar o animal, mesmo sem conhecê-lo, para saber muitas coisas acerca de seu proprietário. Como a graça de Deus é transmitida pelos cristãos? A Igreja a projeta verdadeiramente neste mundo?

Entre os vários usos da palavra "graça", um deles, no acusativo, é algo que favorece prazer, alegria, felicidade ou o que torna a pessoa graciosa, benevolente (Ef 1,6) em paralelo com $\mathrm{Lc} 2,40 ; \mathrm{Cl} 4,6$ e At 7,10. É a benevolência de Deus, livre e universal.

Se a benevolência e a alegria são expressão desta graça divina e, se a Igreja é o espaço da recepção e difusão dos valores divinos, devendo ser a imagem da Trindade, por que muitas vezes, a tristeza do pecado e da culpa sobrepõe à alegria do perdão, recebido por obra da graça? Paulo traz a resposta. Para ele, tais comunidades continuam mortas, não têm o sentimento de gratidão $(R m 6,17)$ e, além disso, cultivam e exaltam os seus próprios méritos, em detrimento daquele que é digno de toda glória: Jesus Cristo. A Igreja deve ser sinal da graça no mundo, pois é o lugar da celebração e do perdão. A ela foi dada a fé que a possibilita de conhecer, em parte, a maravilhosa graça.

Pela graça a comunidade cristã se santifica. Não é critério de salvação uma boa teologia, estudos bíblicos, escolas dominicais, catequese e ricas celebrações. Estas iniciativas ajudam a entender teoricamente a ação gratuita de Deus. É preciso colocar em prática os conhecimentos e ser sinal do amor de Deus à humanidade.

O perdão deve ser, na Igreja, um dos sinais do amor de Deus. Deus, por pura misericórdia, perdoa o pecador que humildemente procura se santificar e tornar a humanidade mais justa, conforme os valores do Reino, apresentados em Cristo Jesus. O verbo "perdoar" quer dizer: soltar, libertar, mandar embora, redimir. No sentido teológico-bíblico, significa libertar das dívidas ou do pecado. Assim como Deus perdoa, em Cristo, a humanidade pecadora, a Igreja, em cada um de seus membros, deve perdoar, cumprindo, absorvendo assim a lei maior do amor $(M t 6,12 ; 18,21)$. 
O que é mais fácil: perdoar ou pedir perdão? Jesus não disse que a missão da Igreja seria fácil. É preciso considerar as duas dificuldades, tanto a tarefa de dar o primeiro passo, em direção ao ofendido, quanto de se dirigir ao ofensor. Não é simples, mas o cristão, à imagem de Deus, que em Cristo resgata a humanidade perdida, deve ser motivado a andar nas duas direções. Ao perdoar, a pessoa percebe que o primeiro cativo a ser libertado é ela mesma.

Quem perdoa lida com as ofensas e, ao dialogar com elas, a pessoa se confronta com o maior ofensor que, muitas vezes, é ela mesma. Pedir perdão e perdoar é um ato nobre, vai além da capacidade humana. Ainda que esteja escrito que "o ser humano é mau e que não há bondade em seu coração", pedir perdão e perdoar não é um ato puramente racional ou emocional, é um ato de pura gratuidade. No Brasil, na época da Ditadura Militar, ao fugir para o exílio, um frade perdoou o seu torturador. Não queria levar consigo, além das marcas da tortura, o próprio torturador. Entendeu que seria mais atormentado se não libertasse o ofensor de seu interior. A Igreja, em suas ações, resplandece a luz da graça. O amor, sinal da graça divina, deve ser demonstrado entre os irmãos, na comunidade e fora dela de forma incondicional. Jesus chamou a ele todos os cansados e oprimidos a fim de aliviar os seus fardos e ensinar a humildade e mansidão. A Igreja deve aprender, em Jesus, a lidar com as dificuldades; nele, o jugo e o fardo são leves e suaves (Mt 11:28-30). A Igreja se reforma constantemente à medida que ela é chamada, não só anunciar um Reino de graça e amor, mas a denunciar toda tentativa de enquadrá-la nas grades deste mundo.

\section{Conclusão}

A título de conclusão, é importante chamar atenção sobre a autoria desta carta e sua ligação com a teologia da graça, ressaltadas em outras epístolas. A Igreja se reforma pela graça, por meio da fé, lendo as Escrituras e colocando-as em prática. Neste sentido, em primeiro lugar, cabe uma palavra sobre a construção do texto de Efésios e, em segundo, sobre algumas ideias a serem consideradas a partir desta reflexão.

A epístola aos Efésios foi questionada. Muitos estudiosos, colocando-a paralelamente à carta aos Colossenses, viram que seu estilo, mais calmo e leve, sem fazer uso de expressões mais agressivas e apologéticas, comuns em outras cartas reconhecidas como "paulinas", se assemelham em forma e conteúdo. 
Um destes estudiosos, Quesnel (2004, p. 120), a fim de resolver o impasse literário, propõe três possíveis esquemas históricos: 1) A carta aos Efésios depende de Colossenses; 2) Colossenses depende de Efésios; 3) ambas são literalmente independentes, porém compostas numa única escola paulina. Segundo este autor, a primeira solução é mais aceita entre os comentadores e eles se valem de um indício textual: "Os testemunhos manuscritos mais antigos não trazem indicação de destinatários".

Ao traçar um paralelo entre estas cartas, Quesnel (1994, p. 123) observa que há uma evolução na teologia paulina. Primeiramente os escritos são endereçados à comunidade gentio-cristã e conta com uma forte cristologia: Cristo é "cabeça"; cabeça da criação; cabeça da igreja. Nele, tudo é reconciliado, principalmente a relação Deus e humanidade (Cl 1:19-20). A epístola aos Efésios retoma os Colossenses a fim de detalhar, mais ainda, uma teologia cristológica, mais universal: "Exprime não somente quem é Cristo em relação à Igreja, mas também quem é ele em relação a Deus, que o deu aos homens, e também em relação a todos os seres, até mesmo em relação às potências celestes. Já bastante universal na epístola aos Colossenses, o Senhorio de Cristo o é ainda mais na retomada de Efésios".

A observação de Quesnel é importante. Se Paulo não escreveu aos Efésios, não há razão porque o verdadeiro autor se fizesse passar por Paulo e endereçasse o escrito aos Efésios e não aos Colossenses. Porém, a terceira hipótese pode também ser considerada e os Pais da Igreja, que tanto fizeram para que o escrito se tornasse canônico, não se oporiam a esta escola. Policarpo, por exemplo, o mártir de Esmirna, mencionara o conteúdo da carta aos Efésios, sem se preocupar com a autoria. Numa circular enviada aos Filipenses (1,3), escreve: "E vós sabeis que é pela graça que fostes salvos, não pelas obras, mas pela vontade de Deus, por meio de Jesus Cristo". 5

A favor da terceira hipótese, Valmor da Silva observa que essa carta foi escrita lá pelos anos 90 e procura ser uma síntese da mensagem de Paulo a um destinatário mais universal: a próxima geração, não a primeira, ainda desestabilizada e israelizada, mas uma igreja unificada, construída sobre os apóstolos e profetas, onde convivem pacificamente judeus e pagãos, sob a manifestação do Espírito. A carta se preocupa em abordar questões de uma Igreja mais global e menos local.

5 Poicarpo de Esmirna, "segunda carta aos Filipenses", in Padres apostólicos. Col. Patrística. São Paulo: Paulus, 1995, p. 139. 
Falar da graça numa Igreja que se reforma é um desafio, por isso consideraram-se alguns tópicos importantes que precisam de mais atenção. Em primeiro lugar, Paulo, mais que nos evangelhos, fala da graça, mas o questionamento sobre a autoria da carta deixa no ar se Paulo é ou não o apóstolo da graça de Deus.

Em segundo lugar, esta reflexão se permitiu responder uma questão: Como interpretar as leituras referentes à graça de Deus e aplicá-las à Igreja hoje. A Igreja é lugar do arrependimento e do perdão, mas, muitas vezes, devido a interesses políticos e eclesiásticos, a misericórdia de Deus é esquecida ou ofuscada. Uma Igreja forte deve se questionar e se preocupar em transmitir, à imagem de Jesus Cristo, "a verdadeira imagem do Deus verdadeiro" ( $\mathrm{Cl} 1: 15-16)$ a toda a humanidade.

\section{Referências}

BÍBLIA de Estudos. Palavras-chave: Hebraico-Grego. 2. ed. rev. Rio de Janeiro, 2011. CROSSAN, J. Dominic; REED, Jonathan L. Em busca de Paulo. São Paulo: Paulinas, 2007.

HARRINGTON, Wilfrid J. Chave para a Bíblia. São Paulo: Paulus, 1973.

QUESNEL, Michel. Paulo e as origens do Cristianismo. São Paulo: Paulinas, 2004.

RADAMACHER, Earl D.; ALLEN, Ronald B.; HOUSE, H. Wayne. O novo comentário bíblico NT, com recursos adicionais - A Palavra de Deus ao alcance de todos. Rio de Janeiro: 2010.

SILVA, Valmor da. Paulo, apóstolo de Jesus Cristo pela vontade de Deus! São Paulo: Paulinas, 2005.

SOUZA, José Neivaldo. Imagem humana à semelhança de Deus. São Paulo: Paulinas, 2010 .

STOTT, John R. W. - A Bíblia fala hoje. A mensagem de Efésios, 1987.

. A Mensagem de Romanos. São Paulo: ABU, 2000.

YANCEY, Philip. O Deus invisível. São Paulo: Editora Vida, 2001.

Recebido: 13/03/2015

Avaliado: 09/04/2015 